\title{
Foreword
}

\section{Sports Medicine Is not Spineless!}

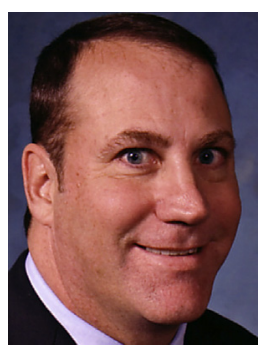

Mark D. Miller, MD Consulting Editor

We try to be all-inclusive and comprehensive in our coverage of topics in Clinics in Sports Medicine. Although my practice does not include spine, spine is certainly a part of a sports medicine practice. At our institution, we are lucky to have not one but two "sports spine" specialists, each covering a Division I college that we care for....and they both get a lot of referrals from those training rooms. These two surgeons, Drs Frank Shen and Adam Shimer, agreed to put together a treatise on the care of spine problems in athletes so that even if you don't actually practice sports spine, you will know when and how urgently to refer your athletes to the spine experts on your sports medicine team.

This issue is well organized and comprehensive. It begins with injury prevention and then focuses on on-field management. What follows is an overview of various spine conditions commonly seen in athletes. Young and old athletes alike are covered, and the important issue of Return to Play is addressed. My sincere thanks to Drs Shen and Shimer-now let's "get back to it."

Mark D. Miller, MD

Division of Sports Medicine Department of Orthopaedic Surgery University of Virginia Charlottesville, VA, USA

Miller Review Course Harrisonburg, VA, USA

513 Half Mile Branch Road

Crozet, VA 22932, USA

E-mail address: MDM3P@hscmail.mcc.virginia.edu 